\title{
A prova da causa do erro no matrimonio romano e o casamento putativo.
}

\author{
Gaetano Sciascia \\ Livre docente de direito romano da \\ Universidade de Roma, contratado pela \\ Faculdade de Direito da Universidade \\ de São Paulo
}

1. Como é sabido, em Roma existe casamento com ef eitos de ius civile (iustae nuptiae), quando os cônjuges têm capacidade de se casar segundo o direito romano (connubium) (1).

Durante o periodo clássico (2), em geral, podem casar validamente os cidadãos romanos. Assim, no que diz respeito ao status civitatis, cumpre distinguir:

a) Os romanos ingenui.

* Ofereço o presente trabalho ao ilustre professor da Universidade de São Paulo que, alem de grande comercialista, conhecido e estimado no novo e no velho continente, frequentemente tratou problemas jurídicos conexos com a cidadania e o casamento. Não obstante o tecnicismo da pesquisa, espero que os leitores, percebendo quanto há de semelhante entre o Brasil e Roma em matéria de nacionalidade das pessoas, possam encontrar nela uma interessante experiência de história do direito. Visando êste objetivo a minha modesta homenagem ao Prof. Waldemar Ferreira, propugnador da necessidade de encarar historicamente o direito moderno, segue a linha científica e didática traçada pelo Mestre.

(1) Ulp. 5,3: Connubium est uxoris iure ducendae facultas.

(2) A lei Canuleia, que concedeu o connubium entre patrícios e plebeus, é provavelmente do ano 445 a. C., logo depois das XII Tabuas. 
b) Os habitantes das colónias (Latini coloniarii) (3) que obtiveram a cidadania ou pelo cargo exercido na propria civitas (4), ou por normas especiais (5), ou por concessão do imperador (6), ou pelo processo da annicuii probatio (lei Elia Sencia) (7).

c) Os escravos alforriados (liberti) que se tornaram cidadãos romanos: $10^{\circ}$ - imediatamente, por força da alforria válida por ius civile $(8) ; 2^{\circ}$ - posteriormente à alforria, tratando-se de escravos libertos por ato não válido segundo o ius civile (Latini Iuniani) (9), que em seguida obtiveram a cidadania ou sendo outra vez alforriados, mas

(3) Chamam-se Latini os que pertencem às coletividades latinas inclusive as colonias, e os escravos não alforriados segundo as formas idóneas por ius civile; cf. nota 9.

(4) Cf. Gai. 1,97.

(5) Ulp. 3,5: lei Visélia de 25 d. C., quanto a quem for guarda por seis anos (posteriormente um senatusconsulto reduziu o prazo a tres anos); Gai. 1,32 c, Ulp. 3,6: edito de Claudio quanto a quem construir um navio com dez mil modios de capacidade e carrear com êste trigo para Roma durante seis anos; Gai 1,33: constituição de Nero, quanto a quem edificar um prédio em Roma, gastando no mínimo metade de seu patrimonio, não sendo este inferior a duzentos mil sestércios; Gai. 134, Ulp. 3,1: constituição de Trajano, quanto a quem tiver em Roma uma padaria por tres anos, com prođução diária não inferior a cem módios de trigo. Já durante a republica, a lei Acília (Riccobono, Fontes, 2 ed., vol. I p. 101) dava a cidadania em premio a quem tivesse acusado de crime eleitoral um magistrado romano, acarretando sua cōndenação.

(6) Cf. Ulp. 3,1 e 5,4.

(7) O Latinus deve provar perante o magistrado ter tido como mulher uma romana ou latina que lhe deu um filho e que o filho completou um ano; cf. Gai. 1,29 a 32; Ulp. 3,3; vide tambem Gai, 1,66.73.80; 3,5.73; Coll. 16,2,5 (Gai.) e 16,3,15 (Paul.). Não é certo que a prova era prevista sòmente pela lei Elia Sencia, cf. Buckland, A text-book of roman law 2 ed., Cambridge 1932 p. 95.

(8) Manumissio vindicta, censu, testamento, cf. Ulp. 1,6.

(9) Cf. Gai. 1,22 a $24 ; 2,275 ; 3,55$ a 72; Ulp. 20,14; Cod. 7,6,1; Inst. 1,5,3. Não são validas por direito civil as manumissões inter amicos, per mensam, per epistulam. 
validamente (iteratio) (10), ou aproveitando-se de normas especiais (11), ou por concessão do imperador (12), ou por anniculi probatio (lei Elia Sencia) (13).

d) Os estrangeiros (peregrini) das cidades às quais Roma concedeu o connubium (14).

Prescindindo de proibições especiais (15), as pessoas mencionadas têm capacidade de casar com as da propria categoria, como tambem com as das outras categorias.

Tendo presente estas distinções, pode-se ler o texto das Institutas de Gaio que ilustra os casos em que pessoas, carecedoras de connubium, podem transformar sua união em iustae nuptiae, provando ter ignorado a falta de capacidade.

2. Gai. 1, 67: (16) Item (scilicet evenit ut liberi, qui statim ut nati sunt parentum in potestate non fiant, postex tamen redigantur in potestatem), si civis Romanus Latinam aut peregrinam uxorem duxerit per ignorantiam, cum eam civem Romanam esse crederet, et filium procreaverit, hic non est in potestate eius, quia ne quidem civis Romanus

(10) Cf. Gai. 1,35; Ulp. 3,4; Vat. Fragm. 221; Fragm. Dosithei 14; ivide tambem Gai 1,167; Ulp. 11,19.

(11) Cf. nota 5 .

(12) Cf. nota 6 .

(13) Cf. nota 7.

(14) Cf. Gai. 1,56.57.74.76 etc. Depois da baixa (honesta missio) o estrangeiro pode obter o connubium.

(15) A proibição mais conhecida é a da lei Pápia Popea relativa aos da classe dos senadores e às actrizes: Ulp. 13,1; 16,2; D. 23,2,23 Cels.; D. Th. t. 44 pr. Paul. Entre 523, o imlperador Justino, tio. de Justiniano, revogou a proibição permitindo o casamento de seu sobrinho com a famosa Teodora, Cod. 5,4,23. Mas existem muitos outros impedimentos particulares, cf. Costa, Storia, 2 ed., Torino 1925 p. 46 e seg.; Solazzi, Atti Accad. Napoli, LIX (1939).

(16) Reporto o texto oferecido na edição crítica de F. de Zulueta, The institutes of Gaius, Oxford 1946. As letras em grifo faltam no manuscrito; os corchetes indicam glosas; os paréntesis angulares indicam reconstruções de palavras omitidas no manuscrito. 
est, sed aut Latinus aut peregrinus, id est eius condicionis cuius et mater fuerit, quia non aliter quisque ad patris condicionem accedit quam si inter patrem et matrem eius conubium sit; sed ex senatusconsulto permittitur causam erroris probare, et ita uxor quoque et filius ad civitatem Romanam perveniunt, et eo tempore incipit filius in potestate patris esse. Idem iuris est si eam per ignorantiam uxorem duxerit quae dediticiorum numero est, nisi quod uxor non fit civis Romana. 68. Item, si civis Pomana per errorem nupta sit peregrino tamquam civi Romano, permittitur ei causam erroris probare, et ita filius quoque eius et maritus ad civitatem Romanam perveniunt, et aeque simul incipit filius in potestate patris esse. Idem iuris est si peregrino tamquam Latino ex lege Aelia Sentia nupita sit; nam et de hoc specialiter senatusconsulto cavetur. Idem iuris est aliquatenus si ei qui dediticiorum numero. est tamquam civi Romano aut Latino $e$ lege Aelia Sentia nupta sit, nisi quod, scilicet, qui dediticiorum numero est in sua condicione permanet, et ideo filius, quamvis fiat civis Romanus, in potestatem patris non redigitur. 69. Item, si Latina peregrino, cum eum Latinus esse crederet, $<e$ lege Aelia Sentia $>$ (17) nupserit, potest ex senatusconsulto, filio nato, causam erroris probare, et ita (18) omnes fiunt cives Romani, et filius in potestate patris esse incipit. 70. Idem constitutum est et si Latinus per errorem peregrinam quasi Latinam aut civem Romanam e lege Aelia Sentia uxorem duxerit. 71. Praeterea, si civis Romanus, qui se credisset Latinum esse, ob id Latinam <uxorem duxerit $>$ (19), permittitur ei, filio nato, erroris causam probare, tamquam si e lege Aelia Sentia uxorem duxisset

(17) A integração é de Huschke.

(18) Faltam tres letras assim integradas por Goeschen e os demais editores; Polenaar supriu: quo modo.

(19) Assim reconstroem todos os editores; mas, como observa de Zulueta no manuscrito o ultimo verbo do período está no plural. 
(20). Item his qui, cum cives Romani essent, peregrinos se esse credidissent, permittitur ex senatusconsulto, filio nato, causam erroris probare, quo facto fiet uxor civis Romana, et filius... (21) non solum ad civitatem Romanam pervenit, sed etiam in potestatem patris redigitur. 72. Quaecumque de filio [esse] diximus, eadem et de filia dicta intellegemus. 73. Et quantum ad erroris causam probandam attinet, nihil interest cuius aetatis filius sit filiave. . (22) si minor anniculo sit filius filiave, causa probari non potest. Nec me praeterit in aliquo rescripto divi Hadriani ita esse constitutum tamquam, quod ad erroris quoque causam probandam (23) 74. Si peregrinus civem Romanam uxorem duxerit, an ex senatusconsulto causam probare possit quaesitum est... (24) hoc ei specialiter concessum est. Sed cum peregrinus civem Romanam consecutus esset, deinde, cum quaereretur an causam manam consecutus esset, deinde, cum quaereretur an causam probare posset, rescripsit imperator Antoninus proinde posse eum causam probare atque si peregrinus mansisset. Ex quo colligimus etiam peregrinus causam probare posse.

(20) No manuscrito está duxissent; a emenda é de Goeschen; Huschke observou que as palavras tamquam até duxisset ficariam melhor colocadas na lacuna precedente.

(21) No manuscrito sete letras são ilegiveis; sua reconstrução é dificil, pois mesmo com a lacuna o sentido do texto é completo.

(22) Goeschen pensou que na lacuna (pouco mais de duas linhas) se afirmasse que pela lei Elia Sencia a causa não se pode provar, se o filho ou a filha é menor de um ano; assim Krueger reconstruiu o texto: filiave nisi forte eorum aliquis, qui e lege Aelia Sentia matrimonium se contrahere putarint erroris causam probare velit; ad hoc enim si minor etc.

(23) Faltam quase tres linhas. Goeschen pensou que Adriano exigisse que o filho tivesse a idade de um ano e Krueger acrescentou que o Gaio não aceitava a consequencia que se queria tirar do rescrito imperial. De Zulueta considera a suposição de Krueger como provavel.

(24) Sobre a lacuna of. mais adiante nr. 6. 
75. Ex his apparet, sive civis Romanus peregrinam sive Romanam uxorem duxerit, eum qui nascitur peregrinum esse, sed si quedem per errorem tale matrimonuium contractum fuerit, emendari vitium eius ex senatus consulto secundum ea (25) quae superius diximus. Si vero nullus error intervenerit, sed scientes suam condicionem ita coierint, nullo casu emendatur vitium eius matrimonii (26).

(25) O texto é defeituoso.

(26) A tradução seguinte corresponde àquela que oferecemos com Alexandre Correia no vol. 2 ido nosso Manual de direito romano S. Paulo 1951: “67. Omesmo se dá (i é, que filhos, que não caem sob o poder do pai desde que foram natos, veem depois a entrar nesse poder) se um cidadão Romano ise casar por ignorancia com uma Latina ou peregrina acreditando que fosse cidadã Romana; se dela teve um filho não tem sobre ele o patrio poder, porque não é o mesmo cidadão Romano, mas Latino ou peregrino, i. é, da mesma condição da mãe, porque nenhum filho segue a condição paterna se não houver conubio entre o pai e a mãe. Mas em virtude de um senatusconsulto é-lhe permitido provar a causa do seu erro; e então tanto a esposa quanto o filho adquirem a cidadania Romana, e desde esse tempo começa êle a estar sob poder do pai. A mesma situação jurídica se dá se, por ignorancia, se casar com uma mulher da classe dos deditícios; mas nesse caso a mulher não se torna cidadã Romana. 68. Igualmente, se uma cidadã Romana se casar com peregrino por erro, pensando ser cidadão Romano é-lhe permitido provar a causa do seu erro e então tanto o filho como o marido adquirem a cidadania Romana e, do mesmo modo, começa logo o filho a estar sob o poder do pai. Idêntica situação jurídica será se casar, nos termos da lei Elia Sencia, com um peregrino, supondo-o Latino; pois esse caso é especialmente previsto pelo senatusconsulto. A mesma situação jurídica de certo moido se dará se se casar com um da classe dos deditícios nos termos da lei Elia Sencia, pensando que fosse cidadão Romano ou Láiino. Salvo que o da classe dos deditícios permanece na sua condição e portanto o filho embora tornado cidadão Romano, não cai sob poder do pai. 69. Igualmente, se uma Latina se casa com um peregrino, nos termos da lei Elia Sencia, crendo ser Latino, pode, em virtude do senatusconsulto e depois de nato o filho, provar a causa do seu erro, tornando-se assim todos cidadãos 
3. Os casos de prova da causa do erro (erroris causae probatio) são enumerados por Gaio na ordem seguinte: $1 .^{\circ}$ O romano se une com latina ou peregrina ou deditícia, julgando-a romana (Gai.1,67).

2. A romana se une com peregrino, julgando-o romano; ou se une com peregrino, tendo-o por latino que aproveita da lei Elia Sencia; ou se une com deditício, jul-

Romanos e entrando desde logo o filho sol o pátrio poder. 70. O mesmo foi determinado se um Latino se cascu, nos termos da lei Elia Sencia, por erro com uma peregrina, tomando-a por Latina ou cidadã Romana. 71. Alem disso, se um cidadão Romano, acreditando-se Latino, por isso casou com Latina, é-lhe permitido provar a causa do seu erro, como se tivesse casado de acordo com a lei Elia Sencia. Igualmente, os que, sendo cidadãos Romanos se acreditassem peregrinos e casassem com mulheres peregrinas é-lhes permitido pelo senatusconsulto provar, uma vez nascido o filho, o seu erro; e por consequência se tornará a mulher cidadã Romana e o filho. não só adquire a cidadania Romana mas tambem cai sob o poder do pai. 72. Tudo o que dissemos do filho, entenderemos como dito tambem da filha. 73 . E no atinente à prova da causa do erro, nada importa de que idade seja o filho ou a filha. sendo menor de um ano, não pode provar a causa. Nem me esquece que num rescrito do divino Adriano foi estabelecido que, no concernente tambem a prova da causa do erro.. 74. Se um peregrino casar com uma cidadã Romana e depois há dúvida sobre se pode pelo senatusconsulto provar a causa. isto lhe foi especialmente concedido. Mas se um peregrino casou com uma cidadã romana e, nascido o filho, em seguida adquiriu a cidadania Romana, e depois como se perguntasse se podia provar a sua causa o imperador Antonino por um rescrito determinou que podia provar a sua causa como se tivesse permanecido peregrino. Donde concluimos que tambem o peregrino pode provar. 75. Do que dissemos resulta que quer um cidadão Romano se case com uma peregrina, quer um peregrino com cidadã Romana o que nascer é peregrino. Mas se por erro tal matrimonio for contraido,é licito, em virtude do senatusconsulto emendar-lhe o vício, conforme o que acima dissemos. Mas se nenhum erro interveio e se se uniram ciêntes da sua condição, em nenhum caso se lhes emenda o vicio do matrimonio". 
gando-o romano ou latino que aproveita da lei Elia Sencia (Gai.1,68).

3. A latina se une com peregrino, julgando-c latino que aproveita da lei Elia Sencia (Gai.1,69).

4. ${ }^{\circ}$ O latino se une com peregrina, tendo-a por romana ou latina e aproveitando da lei Elia Sencia (Gai.1,70).

5. ${ }^{\circ}$ O romano se une com latina, julgando-se latino como se pudesse aproveitar da lei Elia Sencia (Gai.1,71).

6..$^{\circ}$ O romano se une com peregrina, julgando-se peregrino (Gai. 1,71).

$7 .^{\circ}$ O peregrino se une com romana, julgando... (Gai.1,74).

Examinarei a seguir quem pode provar o erro, a natureza do erro, o eventual requisito da prole, o processo da prova e seus efeitos com relação aos cônjuges e filhos.

4. Permite-se a prova do erro, antes de mais nada, à pessoa que errou. Em todos os casos apresentados Gaio supõe que esta faça a prova. No fim do paragrafo 75 fala-se no plural (scientes), mas não há duvida de que aí o jurisconsulto se refere às pessoas consideradas nos casos precedentes, e não aos dois conjuges de cada caso (27).

Assim, numa união sem connubium, cada um dos conjuges poderá provar seu erro, sendo a opinião do outro indiferente.

Em face do conteudo do mesmo paragrafo 75 , onde se exclui que a prova possa ser feita pelos cônjuges que sabiam da falta de capacidade, me parece impossivel sustentar que o cônjuge que não errou possa provar o erro do outro (28). Como veremos, êle porém se aproveita do erro.

(27) S. Solazzi, Glosse a Gaio, Studi Riccobono vol. 1 pag. 131 segs. considera glosas as duas últimas oraçōes do parágrafo 75 , interpretando a palavra scientes como referida aos dois cônjuges de cada caso; mas me parece que a inexatidão apontada é inexistente.

(28) C.f. nota 30 . 
Em Gai.2,142 e 143, como tambem em Gai.3,5 (29) se supõe que a prova do erro seja feita depois da morte do pai. Nas Sentênças de Paulo 4,8,7 (Collatio 16,3,7) é prevista a mesma hipótese. Visto que em todos estes casos o processo aproveita aos filhos, deve-se dizer que os próprios filhos podem fazer a prova, pelo menos após o falecimento do pai. A conclusão é conforme ao princípio geral segundo o qual a prova dum fato deve ser aduzida por quem pretende direitos de tal evento e está confirmada pela analogia da anniculi probatio, em que, segundo outros textos, a prova é aduzida pelo próprio filho (30). Visto que os textos tratam separadamente da prova do erro depois da morte, pode ser que a matéria tenha sido regulada por um senatus-consulto posterior ao da prova do erro.

5. Problema mais delicado é o da natureza do erro.

Para que se possa falar em erro sobre o carater jurídico do casamento é necessário que a relação existente entre os sujeitos preencha em abstrato todos os requisitos dum casamento válido segundo o ius civile. Gaio usa as locuções técnicas para indicar respectivamente o casamento do homem (uxorem ducere) e da mulher (nubere). Iniciando a vida em comum, houve de fato a celebração das cerimonias usuais e os dois elementos necessarios para a existência do casamento, i, é, a affectio maritalis e o honor matrimonii. $\mathrm{O}$ casamento existe; não existem seus efeitos juridicos que os cônjuges ou um deles supõem existir (30 a).

(29) Em Gai. 3,5 a referência ao nosso senatusconsulto é integrada por Coll. 16, 2, 5 (Gai.).

(30) Cf. Gai. 32; Coll. 16, 3, 15 (Paul.). Note-se, porem, que a anniculi probatio pode ser feita tambem pela mãe, posteriormente là morte do pai, cf. Gai. 1, 32.

(30 a) Note-se, tambem sob este aspecto, a analogia com a posse e cf. sôbre a iusta causa da tradição e do usucapião o excelente trabalho de P. Voci na Revista "Studia et Documenta Historiae et Juris" XV (1949) pág. 141 e segs. 
Querendo analisar a condição de cada cônjuge, quer no que diz respeito à sua relação com a condição do outro, quer no que concerne ao alcance do erro, pode-se afirmar um primeiro grupo de regras gerais:

a) Quem erra está em melhor condição do que aquele que não erra (31).

O princípio falha no último caso (nr.7. $)$, em que o erro, aliás desconhecido, deve atribuir-se ao peregrino que se une com romana.

b) Quem erra acredita ser o cônjuge de condição igual à sua ou de condição que se possa tornar igual à sua; ou tambem se julga êle próprịio de condição igual à do cônjuge .

c) Quando o erro recai sobre a condição do outro conjuge, a sua falsa condição é melhor que a verdadeira; quando o erro recai sobre a própria condição, a condiȩão que se supõe é pior que a verdadeira.

Considerando o sexo de cada sujeito, formula-se um segundo grupo de regras:

a) O homem pode errar quanto à propria condição.

b) A mulher não pode errar quanto à propria condição.

Dados estes princípios, aos casos apresentados por Gaio se poderiam acrescentar outros que preenchem todos os requisitos: $8 .^{\circ}$ O cidadão que se une com peregrina ou deditícia, supondo-a latina que aproveita da lei Elia Sencia; 9. A cidadã romana que se une com latino que aproveita da lei Elia Sencia, supondo-o cidadão Romano; 10 . A latina que se une com deditício, julgando-o latino que aproveita da lei Elia Sencia; $11 .^{\circ}$ O latino que se une com peregrina, julgando êle proprio peregrino.

Mas o erro, como se disse, consiste na representação duma situação que, se fosse verdadeira, teria tornado ius-

(31) Ulp. 7, 4 fala em matrimonio contraido por erro entre pessoas disparis condicionis. 
tum desde já ou em futuro o casamento (32). Ora, em dois casos apresentados por Gaio e no último que tirei da analogia isso não se dá.

Quando o romano se une com peregrina (caso $6 .^{\circ}$ ), julgando-se peregrino, não se configura um casamento válido por ius civile nem no presente nem no futuro. Não se configura no presente, pois a falsa representação, se fosse real, não pressuporia nos sujeitos o connubium; não se configura no futuro, porque o peregrino não pode tornar-se cidadão romano por anniculi probatio (33). Entretanto Gaio atribui expressamente ao senatusconsulto a norma em virtude da qual o erro é excusavel. A norma, que por certo é excepcional com relação ao conceito de erro, pode parecer menos grave considerando que entre dois peregrinos sem connubium eventualmente existe um casamento iustum quanto ao direito da civitas do pai (34).

Nãọ diferente é a situação que contemplamos no caso 11. baseado na analogia: o latino que se une com peregrina, julgando-se ele proprio peregrino, não realiza abstratamente um casamento valido e, por isso, seu erro não corresponde a uma situação que, se verdadeira, seria conforme ao direito. Destarte, na falta duma norma expressa

(32) Não é permitida a prova ao romano que se uniu com escrava, a qual posteriormente se tornou livre e romana antes de dar à luz. Prescindindo das evidentes razões politicas que justificam a exclusão, com escrava nem siquer abstratamente pode existir casamento. Compare-se, alias, no texto onde Gaio fala do caso $(1,88)$ a expressão talỉs coitus com a de tale matrimonium referida à união cujo vício é sanavel pelo processo da prova (1,75). Sôbre Gai. 1,85 (o fillho varão do homem livre que se une com escrava, julgando-a livre, nasce livre) cf. Castello, Studi in onore di S. Solazzi, Napoli 1948 p. 141 e segs.

(33) C.f. os textos indicados na nota 7. Obtendo a cidadania, o peregrinus não adquire necessariamente o pátrio poder, Gai. 1,93; cf. as clausulas nas concesões imperiais, Girard, Textes p. 124.

(34) Cf. Gai. 1, 92: secundum leges moresque peregrinorum. Assim iustus em Grai. 1, 77 é com relação ao direito do peregrino. Os modernos falam em matrimonium iuris gentium. 
do senatusconsulto sobre o caso, pode-se duvidar da sua admissibilidade, embora, como no caso $66^{\circ}$, entre dois peregrinos o casamento eventualmente é justo com relação ao direito dêles.

6. Consideração particular merece o caso $7 .^{\circ}$, não somente porque aí, como se disse, a situação errada não dá lugar a um casamento válido, mas tambem porque a espécie constitui uma exceção à regra a) do primeiro grupo, segundo a qual quem erra está sempre em condição melhor do que o cônjuge que não erra. Alem disso, o texto de Gaio que apresenta a hipótese é lacunoso.

Gai.1,74 supõe que um peregrino casou com uma romana. Não sabemos qual ẹ o erro previsto; i.é, se o peregrino se julgou êle próprio romano ou julgou peregrina a mulher. O espaço da lacuna, aproveitando das palavras ainda visiveis segundo a $3 .^{a}$ edição de Gaio dada por Krueger e Studemund (35), não é suficiente para a reconstrução das duas hipóteses, de forma que devemos escolher uma ou outra.

Se o peregrino se julga êle próprio romano e casar com uma cidadã romana, não há dúvida de que a falsa representação concretiza um casamento abstratamente válido segundo o ius civile, exatamente um casamento entre dois cidadãos. Mas, se êste fosse seu erro, a hipótese não se conciliaria com o princípio c) do primeiro grupo de

(35) Nos Suplementa de G. Studemund contidos na mesma edição (pag. XXIII) as tres linhas lacunosas do parágrafo 74 são descritas assim (as letras em grifo são incertas) :

Siperegrinuscruxoremdixeritanexs. cbpro

+arepossitquesitume

cupquisipsedecepimalicroma

Na segunda linha, adverte Studemund, depois de quesitume parece que estava a letra $s$; na terceira linha as letras 17 e 18 são incertissimas. A linha seguinte começa diretamente com as palavras visiveis: hoc ei specialiter concessum est. 
regras, segundo o qual, quando o erro recai sobre a própria condição, a condição que se supõe deve ser pior que a verdadeira.

À parte o alcance da exceção, do ponto de vista prático admitir a prova de tal erro significaria convalidar os casamentos dos peregrinos com as romanas dando lugar a abusos e fraude. Acresce a excepcionalidade dos casos em que o senatusconsulto permite a prova do erro sobre a própria condição; faculdade esta evidentemente reservada aos cidadãos, pois o caso $11 .^{\circ}$ que tiramos da analogia é muito duvidoso.

Resta-nos, portanto, a outra hipótese de erro: o peregrino se uniu com cidadã romana, julgando-a peregrina (36) ou latina. Aqui a opinião de quem erra configura apenas um casamento válido segundo leges moresque da civitas a que o peregrino pertence (37). Dado que o senatusconsulto admitia expressamente a convalidação no caso análogo (nr.6. ${ }^{\circ}$ ) do romano que se uniu com peregrina, julgando-se peregrino, podia ser justificada a dúvida.

Mas a hipótese não preenche o requisito da regra c) vista acima, de que, quando o erro recai sobre a condição do outro conjuge, a sua falsa condição é melhor que a verdadeira; pois a cidadã romana está evidentemente em condição melhor que a peregrina ou latina, i. é, em condição melhor que a que erradamente lhe atribui o conjuge.

Ora, tendo presente que no parágrafo 73 Gaio tinha discutido a exigência de o filho ter completado um ano, quando se tratava de aproveitar da lei Elia Sencia (38), e considerando que no parágrafo 75 o jurisconsulto expressamente afirmava possivel a convalidação do casamento

(36) Aceita esta hipótese H. J. Roby, Roman private law, 1902 p. 39 .

(37) Cf. antes nota 34 .

(38) Cf. antes notas 22 e 23. 
contraido por erro entre um peregrino e uma cidadã romana (39), com os vestígios das letras incertas indicadas por Studemund, proponho a seguinte integração da lacuna $(40)$ :

Si peregrinus civem Romanam uxorem duxerit an ex senatusconsulto causam probare possit quaesitum est; ex lege Aelia Sentia probare causam non potest, quia ipse peregrinus civis Romanus non fit. Sed hoc ei specialiter concessum est. (41)

A lacuna da segunda linha dá para a integração proposta, visto que o título da lei podia ser abreviado (42); na terceira linha a integração enche exatamente o espaço vazio, mas a palavra peregrinus pode ser substituida por outras que não alteram o valor da áfirmação (por ex. hoc modo, ou eadem lege etc.).

Quanto ao fundo, parece-me que a integração corresponde aos princípios gerais. O peregrino, como se disse, não alcança a cidadania por anniculi probatio (lei Elia Sencia). Alem disso, assim como no caso $6 .^{\circ}$, acima ilustrado, embora a situação errada não coincida com um casamento abstratamente valido e, porisso, faltando a norma expressa do senatusconsulto, a solução deva ser negativa (causam probare non potest), os imperadores chegam a permitir a prova (concessum est). O proprio Gaio, aliás no parágrafo seguinte aproxima os dois casos; o do ro-

(39) Que a prova é admitida se dedus tambem do fim do paragrafo 74, segundo o rescrito do imperador Antonino Pio.

(40) Não me foi possivel consultar as velhas edições de Krueger, nas quais o autor tinha proposto uma integração que depois refutou por não combinar com o espaço; cf. Krüger, 3 edição, p. 18.

(41) Tradução: "Se um peregrino casar com uma cidadã Romana, há iduvida se pode pelo senatusconsulto provar a a causa. Não o pode pela lei Elia Sencia, pois em virtude dela o peregrino não se torna cidadão romano. Mas isto lhe foi concedido de modo especial".

(42) Cf. a nota à linha 3 em Krueger, 3 edição, p. 18. 
mano que se une com peregrina e o do peregrino que se une com romana.

7. O requisito da prole é exigido em todos os casos em geral, nem importa que se trate de filho ou de filha, como aliás era estabelecido quanto à annicluli probatio (43); mas quando um dos sujeitos quer aproveitar da lei Elia Sencia, i.é quando o erro se baseia sobre a existência futura do connubium, podendo o cônjuge se tornar cidadão romano pela prova de ter havido um filho o qual completou a idade de um ano, evidentemente é necessário que o filho tenha a idade mínima (44).

Note-se que apenas o nascimento do filho, e não tambem sua idade de um ano, é exigido para convalidar as uniões entre cidadão que se julga peregrino e a peregrina. Neste caso, em que o senatusconsulto operava a mais ampla concessão, não precisava a idade do filho, visto que o erro de se acreditar peregrino não teria permitido em tese o benefício da lei Elia Sencia. A anniculi probatio não se refere aos peregrinos, mas aos latinos.

8. Não temos elementos para ilustrar o processo da prova. E' provavel que as autoridades perante as quais corre o feito são as competentes no caso de anniculi probatio; o pretor em Roma e o governador na província (45).

Para a anniculi probatio se exige a deposição de sete testemunhas. Pode-se supor que o mesmo numero precisa para a erroris causae probatio, pelo menos quando o sujeito aproveita da lei Elia Sencia. Aliás, tratando-se de casamento, o número das testemunhas não é exagerado, pois às cerimonias relativas assiste sempre muita gente.

(43) Gai. 11, 32 a. Pelo contrário, nas uniões por erro entre livres e escravas, até Vespasiano (anos 69 até 79 d. c.), o sexo da prole tinha importancia, cf. Gai. 1, 85.

(44) Cf. antes nota 22 .

(45) Gai. 1, 29. 
Lembre-se que a confarreatio exigia a presência de dez testemunhas (46) e a coemptio de cinco, no mínimo (47).

9. Devemos agora examinar os efeitos da prova.

Quanto aos cônjuges, o efeito da prova é que o que não é çidadão, se torna romano e como tal goza de todos os direitos. A cidadania é excluida para os deditícios, que, como é sabido, em nenhum caso podem alcançá-la (4.8).

Quanto aos filhos, a prova lhes dá a cidadania. Ern particular o filho da união de duas pessoas, entre as quais não há connubium, não é cidadão. Até Adriano a regulamentação é a seguinte: se um dos pais é peregrino, o filho, pela lei Minícia, nasce peregrino (49); se a mãe é latina, pela regra do ius gentium, o filho é latino (50); sendo a mãe romana e o pai latino, havia dúvidas quanto a cidadania do filho (51). O senatoconsulto relativo à prova do erro, que não é posterior a Adriano (52), concede a cidadania aos filhos nos casos indicados.

As normas do senatosconsulto visam evidentemente favorecer os filhos; Gaio as refere com relação ao fato de os filhos cairem sob pátrio poder, i.é, de se tornarem legitimos (iusti); o processo é pe̊rmitido apenas quando existe prole.

(4:6). Gai. 1,112; Boethius in Cic. top. 3,14. Sôbre a prova do casamento em Roma e nas províncias cf. E. Cuq, Manuel, Paris 1928 p. 164.

(47) Gai. 1, 113.

(48) Cif. Gai 1, 15 e 26.

(49) Cf. Gai 1, 15 e 26. Sôbre as observações criticas feitas por Gaio, cf. S. Perozzi, Scritti Giuridici, Milano 1948, vol. III pág. 566.

(50) Gai. 1, 78.

(51) Gai. 1, 80.

(52) Cf. mais adiante, Gai. 2, 142 e 143, onde o senatoconsulto de iniciativa de Adriano (anos 117 até 138 d. C.) pressupõe que já exista o senatoconsulto relativo à prova do erro no casamento, B. Biondi e V. Arangio Ruiz, Acta divi Augusti, Romae 1945, pág. 264 colocam o nosso senatoconsulto nos tempos de Otaviano Augusto; Volterra, Nuovo Digesto Italiano, h. v., (p. 17 da separada) nos de Adriano. 
Sendo o pai deditício, os filhos não podem caír sob seu poder, porque a patria potestas é considerada peculiar aos romanos (53), nâo podendo existir se um dos sujeitos não é cidadão (54). No caso, o filho se torna imediatamente paterfamilias, pois a mãe em Roma não pode ter pátrio poder (55). Alem disso o filho não terá agnatos, i.é, pessoas ligadas com ele em parentesco civil pela linha paterna, e em consequencia os que lhe possam suceder $a b$ intestato ou que lhe possam exercer a tutela prevista na lei das XII Tábuas (56).

Caindo o filho sob patrio poder, êle se torna heres suus do paterfamilias. Gai.2,142 nos informa que se isto acontecesse depois de o paterfamilias ter feito testamento, a princípio, mesmo tendo nomeação ou deserdação daquele que se teria tornado suus, assim como se dava pela adopção (57) ou pela conventio in manum (58), romper-se-ia o testamento. No seguinte parágrafo 143 o jurisconsulto refere que Adriano providenciou para que, havendo a prova do erro depois da morte do paterfamilias, o testamento continuava válido, desde que o filho que se tornava então suus, tivesse sido considerado nele (59); ao passo que o testamento se rompia no caso em que a prova do erro fosse

(53) Gai. 1, 55.

(54) Ulp. 10, 3; Gai. 1, 128.

(55) Gai. 1, 104.

(56) Gai. 1, 155. Não se exclui a probabilidade de que o proprio senatusconsulto da erroris causae probatio contivesse disposições a respeito da tutela; mas Grai. 1, 173 e Ulp. 11, 2 e 20 até 23, falando mos tutores instituidos por senatusconsultos não mencionam o caso; a lei Atília V, em Roma, e Julia e Tícia, nas pronvíncias (Gai. 1, 185 $=$ Inst. 1,20 pr.; Ulp. 11, 18), estavam em vigor.

(57) Gai. 1, 138.

(58) Gai. 1, 139.

(59) Ne scilicet diligenter facta testamenta rescinderentur eo tempore quo renovari non possent; i-é, para os testamentos feitos com cuidado se não rescindirem quando não mais pudessem se renovar (Gai. 1, 143). A regra Catoniana não se aplica à nomeação de herdeiro, D. 34, 7, 3. 
feita durante a vida do pai, pois o testador podia sempre renovar o testamento.

Dado que os latinos não tinham capacidade de fazer testamento e que os peregrinos não podiam testar segundo o ius civile, a regulamentação ilustrada por Gaio devia aplicar-se somente nos casos indicados acima dos numeros $1 .^{\circ}, 5 .^{\circ}$ e $6 .^{\circ}$; i.é, quando o pai já era romano.

Gai.1,75 por duas vezes fala em emendare vitium matrimonii e a mesma expressão se encontra em Gai.1,87 (60). Trata-se de convalidação ex tunc ou ex nunc?

Karlowa opina que a convalidação opera ex tunc (61); Perozzi acha que os simul de Gai.1,65 e 68 indicam, pelo contrário, que a convalidação não retrotrai seus efeitos, considerando porem verossimil a outra opinião (62).

$\mathrm{Na}$ verdade os simul nos lugares citados podem indicar apenas que o filho recai sob pátrio poder do pai no mesmo instante em que se dão os outros efeitos da prova. Mas em Gai.1,67 se diz que ex eo tempore incipit filius in potestate patris esse; em Gai 1,68 se encontra outra vez incipit (começa); e Gaio enfeixa todos os casos apresentados na hipótese geral de que os filhos postea recaem sob pátrio poder (63). Alem disso, uma prova do efeito ex nunc da convalidação do matrimonio contraido por erro se deduz do fato de que, mesmo depois do senatusconsulto, como se disse, o testamento onde havia consideração de quem posteriormente se teria tornado suus, se podia romper.

A convalidação, portanto, operaria ex nunc, desde o momento em que se fez a prova (64).

(60) Solazzi, loco citato, acredita glossados ambos os textos; mas seus argumentos são tão complexos e artificiosos que prefiro evitar referi-los e refutá-los. E suficiente lembrar que emendare se encontra tambem em Gai. 3, 25 e 3, 41 e ainda por certo Gai. 3, 33 b.

(61) O. Karlowa, Roemische Rechtsgeschichte, vol. II p. 264.

(62) S. Perozzi, Istituzioni, 2 edição, vol. I p. 516 n. 2.

(63) Gai. 1,65.

(64) Sobre o efeito retroativo da convalidação no direito romano, os autores, dada a complexidade do assunto, são muito prudentes, cf. por ex. Betti, Istituzioni (1947) p. 185. Windscheid I § 
10. Não é inutil agora apreciar os princípios ilustrados em conexão com o conceito de casamento em Roma e no direito moderno.

A erroris causae probatio, como diz Gaio, emenda o vício do matrimonio, i.é, atribui efeitos de ius civile a uniões que, por falta da capacidade das pessoas, são consideradas relações de fato sem consequências quanto ao direito dos romanos.

Desde que o casamento em Roma é encarado como relação de fato e que o elemento jurídico não lhe altera a natureza objetiva, a prova da causa do erro sobre êste elemento não pode ter nenhuma influência sobre o fato do casamento. O casamento existe ou não existe, sendo indiferente para sua existência tanto o connubium quanto a ignorancia de sua falta por parte de ambos ou de um dos cônjuges.

Como é sabido, no matrimonio romano a vontade de viver juntos more uxorio não é apenas, como no direito canónico e no moderno, a vontade inicial, mas uma vontade atual e duradoura. Desde que o elemento psicológico da affectio e o elemento material da convivência desaparecem, o matrimonio acaba pelo divórcio (65). Tendo presente esta possibilidade, é natural que o cônjuge que errou acreditando ter o connubium com o outro ou jul-

83 nega o efeito retroativo se o ato era nulo por defeito de forma ou em razão de bem público, ressalvando sempre os direitos dos terceiros; Dernburg I $\S 122$ exclui a retroatividade quando a nulidade deriva de proibição legal, cujo efeito seria burlado, e quando deriva de vícios de forma legal. Note-se que os dois pandetistas mencionam como exemplo D. 23, 2, 65, 1 Paul. que, no caso de convalidacão de matrimonio contraido contra mandata nega o efeito retroativo quanto aos filhos (et ideo postea liberos natos ex iusto matrimonio legitimos esse).

(65) Cf. a clara e perspícua ilustração geral do conceito romano de casamento feita por A. Ravà, Lezioni di diritto civile sul matrimonio, 3 edição, Padova 1935 pág. 12 e segs. Cíf. também meu trabalho, Divórcio e direito romano na Revista Investigações, S. Paulo 1951. 
gando poder obte-lo posteriormente, depois de descoberto seu erro, tem a alternativa de acabar a relação conjugal ou de transformá-la, segundo o senatusconsulto, num matrimonio com efeitos de direito romano. O senatusconsulto não restringe de modo algum o elevadissimo conceito romano de liberdade matrimonial.

O erro, portanto, não recai sobre a existencia do casamento, mas apenas sobre seu requisito necessário para originar efeitos de direito romano (66). Destarte, o processo da prova não transforma um matrimonio inexistente num matrimonio existente, mas apenas opera a conversão dum matrimonio puro e simples num matrimonio com consequências jurídicas civis. A principal delas é a legitimidade dos filhos.

Assim conceitualmente diversa é a convalidação permitida pelo senatoconsulto da ratificação do casamento prevista no art. 211 e no art. 216 do código civil. O legislador brasileiro, para a ratificação, exige que a pessoa adquira a necessária capacidade, dando efeito retroativo; a ratificação sana um casamento que é anulavel, ao passo que a prova do erro da foros dé jurídico a um casamento que como casamento de fato é perfeito.

As mesmas observações se podem fazer com relação à convalidatio simplex prevista nos canones 1.133 e segs. do Codex Iuris Canonici; esta convalidação, porem, não tem efeitos retroativos (67).

Consideração especial merecem as relações da erroris causae probatio com o casamento putativo.

(66) Como vimos, nos casos $6^{\circ}$ e $7^{\circ}$, como talvez tambem no $11^{\circ}$, são suficientes os efeitos de ius gentium.

(67) Cf. F. M. Cappello, De Sacramentis, vol. 5: De matrimonio, 5 edição, 1947 pag. 843. 
11. A prova da causa do erro parece ter certa analogia com o instituto do casamento putativo (68).

Por certo, em ambos os casos, se favorecem de modo especial os filhos e, no que diz respeito à construção juridica, a ficção que deriva do erro, no casamento putativo, até o momento da declaração de nulidade da união, corresponde à ficção originada da erroris causae probatio posteriormente à prova.

Mas profundas são as diferenças entre os dois institutos. $O$ senatoconsulto não visa proteger a boa fé, pois a prova do erro aproveita mesmo ao cônjuge ciente. Alem disso, no casamento putativo, o conhecimento do erro assinala o fim dos efeitos jurídicos, ao passo que pelo senatusconsulto a união se torna jurídica conhecendo-se o erro, isto é, aduzindo-se-lhe a prova.

$\mathrm{O}$ direito clássico ignora o instituto do casamento putativo (69). Costuma-se citar como primeiro exemplo um texto da Compilação justinianeia (70).

(68) F. A. Pires da Lima, O casamento putativo, Coimbra 1930 pag. 34, no capítulo dedicado à evolução histórica do instituto, refere os casos de Gaio.

(69) No direito ingles o providencial instituto do casamento putativo não existe: quando o casamento é anulado por não se consumar, por doença mental ou venerea, estado de gravidez não causado pelo marido, existentes no momento da celebração, os filhos se tornam ilegitimos; cf. a sentença das High Courts of London de 30.11.1948 reportada com o comentário de E. D. Nissim em Temi XXV (1949) pag. 262 e segs.

(70) Cf. Vieira Ferreira, O código civil anotado, Rio de Janeiro 1922, ao art. 221; F. Vassalli, Matrimonio putativo em Nuovo Digesto Italiano, Torino 1939. Ambos os autores citam tambem C. 5, 5, 4; mas a constituição de Teodósio Í e outros (talvez do ano 375 d. C.) fala apenas de isenção do confisco das doações nupciais nos casos de grave erro ou de menoridade, não podendo afirmar-se se as doações continuam válidas; aliás, para a isenção de penas cf. tambem Coll. 6, 5, 1 e 2 com constituições de Diocleciano (anos 287 e 291 d. C.) contidas nos códigos Gregoriano e Hermogeniano. Um 
No Digesto, livro 23, titulo 2 (da celebração do casamento), fragmento 57 a (71), o jurisconsulto Marciano, anotando um trecho desconhecido do livro 2 sobre os adultérios de Papiniano (72), reporta a seguinte constituição dos imperadores Marco Aurelio e Lucio Vero:

D.23,2, 57 a In libro secundo de adulteriis $\mathrm{Pa}$ piniani Marcianus notat:

Divus (73) Marcus et Lucius imperadores Flaviae Tertullae per mensorem libertum ita rescripserunt: "Movemur et temporis diuturnitate, quo ignara iuris in matrimonio avunculi tui fuisti, et quod $a b$ avia tua collocata es, et numero liberorum vestrorum: idcircoque cum haec omnia in unum concurrunt, confirmamus statum liberorum vestrorum in eo matrimonio quaesitorum, quod ante annos quadraginta contractum est, perinde atque si legitime concepti fuissent". (74)

caso análogo é referido em Coll. 6, 5, 3 cuja fonte é o liber singularis de adulteriis de Papiniano.

(71) Nas velhas edições do Corpus Iuris o fragmento é reportado como se fosse um parágrafo do texto precedente, cujo autor é o mesmo Marciano.

(72) Papiniano escreveu um comentário de dois livros à lei de Augusto e coligiu num unico livro casos conexos com a mesma lei Julia dos adultérios. Dúvidas sobre a autenticidade do livro único levanta agora $\mathrm{F}$. Schulz, History of roman legal science, Oxford 1946 p. 188 e 238; mas a campanha (sic) contra os libri singulares (cf. agora Guarino, Storia del Diritto romano, Milano 1948, pág. 364 e 321) é um exagero, cf. A. Arthur Schiller, The Jurists and the Prefects of Rome, Mélanges De Visscher (1949) vol. II pág. 328 n. 36 (separata).

(73) Mommsen emenda divi.

(74) Tradução: "Ao livro segundo dos adultérios de Papiniano Marciano anota: Os divinos imperadores Marco e Lucio, por intermedio dum liberto chefe do quartel enviaram o seguinte rescrito a Flavia Tertulla: "Movem-nos o longo tempo em que ficaste casada com teu tio materno ignorando as leis, o fato de a tua avo ter-te feito casar e o numero dos filhos nascidos da união; porisso, concorrendo todos estes elementos, confirmamos a condição dos fi- 
Os divi fratres, que reinaram juntos desde o ano 161 até o ano 172 d.C., reconhecem como legítimos os filhos nascidos de matrimonio sem connubium (75), desde que concorram os seguintes requisitos: a posse continua do estado de casada da mãe (76), a ignorancia por parte desta da norma que proibe o casamento entre colaterais de terceiro grau (77), a iniciativa da avó para a conclusão do casamento e o grande número de filhos (78).

Sustentando que na Compilação justinianeia o rescriło teria valor de mera notícia histórica, Silvio Perozzi afirma

lhos havidos de um matrimonio contraido há quarenta anos, considerando-os como se concebidos legitimamente".

(75) C.f. Gai. 1, 59; Ulp. 5, 6.

(76) Falando em posse de estado observo que no fragmento não se usa a expressão possessio, reservada às coisas corpóreas. Sobre a terminologia cf. Peterlongo, Il possesso di stato nelle fonti romane, Studi Albertoni, vol. II pag. 191 segs., que entretanto não consegue eliminar o testemunho do edito de Claudio (Girard, Fontes p. 189) em que se encontra a locução possessio civitatis. Provavelmente, ja no fim do periodo classico, a terminologia sofreu alterações.

(77) Cf. Gai. 1, 62 e 63; Ulp. 5, 6; Coll. 6, 2, 2. Sobre a excepção quanto ao tio paterno cf. tambem Tacito, Ann. 12, 6. Constancio reestabeleceu a proibição em todos os casos, C. Th. 3, 12, 1; Gai Epit. 1, 4, 3; Inst. 1, 10, 3.

(78) Evidentemente se trata de elementos de fato, pois o consentimento do ascendente de sexo feminino não tem nenhum efeito para o casamento e o numero de filhos aproveita a quem os tiver (ius liberorum) e não aos propriôs filhos. Sobre o texto cf. tambem G. Lombardi, Ricerche in tema di ius gentium, Milano 1946 p. 42. Mas a forma do rescrito pode sofrer críticas: o adjetivo possessivo vestrorum não está certo em discurso dirigido a uma única pessioa (Flavia Tertulla); a referencia à duração da união não deixa entender se os quarenta anos constituem tempo necessário ou apenas indicação informativa sem efeito especial. 
que o direito vigente, ilustrado por Gaio (79), não foi alterado pela decisão imperial (80).

Mas, segundo os critérios que devem orientar a interpretação do Corpus Iuris considerado como um conjunto de leis ( 81$)$, deve-se observar, contra a opinião do simples valor histórico da referencia, que os Compiladores incluiram a lei de Marciano na sedes materiae, dando-lhe assim o maior realce para os fins legislativos; eliminando outrossim o texto anotado de autoria de Papiniano, eles evidentemente quiseram salientar ainda mais o conteudo da constituição imperial. Com efeito, entre os dois jurisconsultos, Marciano e Papiniano, muito maior foi a fama gozada por êste na idade justiniana (82) e a preferência dada ao outro é um claro indício da maior importancia legal atribuida ao rescrito em face do caso apresentado por Papiniano. Este jurisconsulto, quasi certamente, não considerava a decisão imperial (83).

Entretanto, quanto ao direito clássico, as fontes negam qualquer efeito civil às uniões sem connubium (84), seja com relação aos sujeitos, seja com relação aos filhos ha-

(79) Cf. Gai. 1, 64; cf. Gai Epit. 1, 4, 8; Inst. 1, 10, 12.

(80) S. Perozzi, ob. cit. vol. I p. 437 n. 4 ; no mesmo sentido, Scarlata-F'azio, Principi vecchi e nuovi nell'attività giurisdizionale dei divi fratres, Catania 1939 p. 57.

(81) Cf. S. Riccobono, Lineamenti della storia delle fonti e del diritto romano, 2 ed., Milano 1949 pag. 218 e segs.

(82) Cf. Massei, Le citazioni degla giurisprudenza classica nella legislazione imperiale, Studi Ferrini, Università di Pavia, Milano 1946 pag. 475 .

(83) As anotações muitas vezes põem em dia o 'exto anotado; cf. o meu estudo em Bullettino dell'Istituto di Diritto Romiano 50 (1947) p. 410 segs.

(84) Cf. os casos de nulidade coligidos por Gaudemet, Iustum matrimonium, Courtrai 1949 (separada?) p. 314 n. 22 e 23. O concubinato pode ser considerado à parte, porque nele não há casamento por falta da affectio e do honor. 
vidos (85); e no que diz respeito ao instituto do casamento putativo, assim se exprime Perozzi: “É bene avvertire che data la natura del matrimonio romano, l'idea del matrimonio putativo, così familiare ai moderni, doveva essere di necessità ai classici estranea. Essi avrebbero dovuto scinderla in due; distinguere cioè tra matrimonio creduto esistente, mentre non è, e matrimonio esistente e creduto giusto, mentre è ingiusto" (86).

Mas teoricamente é muito dificil a ficção da existencia dum fato, o casamento, e na matéria os clássicos não sentiram esta necessidade em face da absoluta liberdade dos cônjuges. Por certo, a ficção dum elemento jurídico como o connubium se podia construir mais facilmente. O processo da prova da causa do erro se limitou a convalidar as uniões para o futuro. A regulamentação classica se inspira em razões de ordem politica e se encara no movimento geral de romanização dos povos (87).

$\mathrm{O}$ direito justinianeu, conforme sua orientação de conceber como direitos institutos de mero fato, está preparado para acolher o conceito de matrimonio putativo, que mais tarde foi tão brilhantemente elaborado pela doutrina dos canonistas, baseada na proteção da boa fé.

Mas talvez entre a erroris causae probatio e o casamento putativo as conexões historicas e dogmáticas sejam meramente artificiais.

(85) Entretanto em D. 42, 5, 17, 1 e 19 pr. Ulpiano, sendo nulo o matrimonio, reconhece à mulher a qualidade de credora privilegiada para obter a restituição dos bens, que em face de tal nulidade não têm carater de bens dotais.

(86) Perozzi loco citato. Cf. também E. Weiss, Institutionen des roemischen Privatrechts als Einfuerung in die Privatrechtsordnung der Gegenwart, 2 ed., Basel 1949 p. 100.

(87) Cf. recentemente F. De Visscher, La cittadinanza romana, Napoli 1949. 


\section{Apostila}

O Prof. Francisco de Zulueta da Universidade de Oxford, a quem fiz saber minha integração de Gai. 1,74 depois de entregar ao prelo o presente trabalho, enviou-me seu parecer sôbre o ponto. Apresento em seguida suas preciosas observações.

"Gai. 1,74.

"Krueger, ed. 1877: "an et is causam probare possit quaeritur." Then he adds: Ex casu qui proxime sequebatur, haec fere ex ductibus (conf. C. a) posse videntur: probare causam non potest quamvis ipse postea civitate Romana $a b$ imperatore donatus sit nisi hoc ei specialiter etc."

"E. Dubors, Institutes de Gaius, Paris 1881, would have given the above, and the conjectures before Studemund's Apographum (valueless).

"Your integration of V. 20 1. 1: ex lege Aelia Sentia probare. Nothing to the contrary has been read.

"Your integration of 1. 3: quia for the usual quamvis is justifiable because Suppl. has quis (a) which according the Studemund's Proemium p. XX init. means that quia is equally possible. quis $=$ quamvis means that it should be quis (q com o cabo cortado) (Apogr. p. 291). But your peregrinus is nothing like what Suppl. suggests as possible.

"quia written in full is found in 1,37 (V. 9 1. 22), I daresay elsewhere, though of ten abbreviated.

"Huschke 1886 read: "Si peregrinus (cum civem Romanum se crederet) civem Romanam uxorem diuxerit, an ex senatus consulto causam probare possit quaesitum est. Nec tamen potest, quia id peregrino senatus consulto non datur, quamvis ipse deceptus male civem Romanam duxerit, nisi hoc ei specialiter concessum est.

"His sucessor, Kuebler has dropped these conjectures; I suppose because they contradict $\S 68$. 
Your Suggestions - not much palaeographical objection. They depend on the argument. I think the dif.ference from $\S 68$ must be that in $\S 74$ no error is supposed. I think that this is also your view. But I doubt the L. Aelia Sentia having be mencioned, because it is too obvious that it would not apply. And if it was mencioned, I don't think your "quia ipse peregrinus civis Romanus non $f i \iota "$ is at all convincing."

Ora em face da perspicuas observações do grande romanista ingles, justifico ainda minha integração da lacuna: 1) Peregrinus... non fit, como eu disse, podia ser hoc modo ou hac lege. . non fit. $\mathrm{O}$ estilo é por certo melhor assim; 2) Contesto que seja obvio que a lei Elia Sencia não se aplique ao caso do peregrino que se une à Romana julgando-a latina que aproveite da lei e remeto ao que escrevi acima sôbre o caso $6 .^{\circ}$ de Gaio; a regulamentação do caso $20^{\circ}$ e do caso $4 .^{\circ}$ autoriza a dúvida de que a anniculi probatio diz respeito ao peregrino; mas no caso, sendo a mulher Romana, nenhuma vantagem dá ao peregrino a falsa opinião de que ela de latina se possa tornar Romana; 3) Assim, tambem neste caso subsiste erro. $\Lambda$ diferença com o caso previsto no $\S 68$ é evidentemente a seguinte: no $\S 68$ a Romana erra julgando latino o peregrino; no $\S 74$ o peregrino erra julgando latina a Romana. O erro, como se viu, é encarado sempre como próprio de um só dos sujeitos e, ressalvados os filhos (supra p. 378), a prova do erro é permitida sòmente a quem errou.

Quanto à integração proposta por HuschKe e depois refutada por KUEBLER, remeto ao que observei à pág. 381 e seg̣. 